\title{
WAWACAN MAHABARATA \\ KARYA R. MEMED SASTRAHADIPRAWIRA DKK. (Kajian Struktural dan Etnopedagogik)
}

\author{
Fajar Sukma Nur Alam \\ STKIP Muhammadiyah Kuningan \\ Pos-el: aa_ajay89@yahoo.co.id
}

\begin{abstract}
Abstrak
Penelitian ini bertujuan untuk mendeskripsikan struktur wawacan Mahabarata dan nilai etnopedagogik yang terdapat di dalamnya. Sumber data penelitian ini adalah buku Wawacan Mahabarata karya R. Memed Sastrahadiprawira dkk. Dalam penelitian ini digunakan metode deskriptif. Data dikumpulkan melalui teknik studi pustaka. Data yang terkumpul diolah dengan teknik analisis unsur langsung. Berdasarkan hasil penelitian ditemukan bahwa struktur formal Wawacan Mahabarata meliputi guru gatra, guru wilangan, guru lagu, watak pupuh, dan sasmita pupuh. Struktur naratif Wawacan Mahabarata memiliki tema sosial, ada 162 tokoh, latar cerita (tempat, waktu, suasana), dan alur maju. Nilai etnopedagogik dalam cerita ini tergambar dari moral kemanusiaan, yakni moral manusia terhadap Tuhan, moral manusia kepada diri pribadi, moral manusia kepada manusia lain, moral manusia kepada alam, moral manusia kepada waktu, dan moral manusia dalam mencapai kepuasan lahir batin.
\end{abstract}

Kata kunci: wawacan, struktural, etnopedagogik

\section{WAWACAN MAHABARATA OF R. MEMED SASTRAHADIPRAWIRA et al. LITERARY WORKS \\ (Structural and Ethnopedagogic Studies)}

\begin{abstract}
This study aims to describe the structure of Wawacan Mahabharata and its ethnopedagogic values. The data source of this study data is the book Wawacan Mahabharata of R. Memed Sastrahadiprawira et al. This study used descriptive method. Data collected through literature study techniques. The collected data is processed by direct element analysis technique. Based on the research results, it is found that the formal structure of Wawacan Mahabharata includes guru gatra, guru wilangan, guru lagu, watak pupuh, and sasmita pupuh. The narrative structure of Wawacan Mahabharata has a social theme. There are 162 characters, story background (place, time, atmosphere), and forward sequel. The ethnopedagogic value in this story is depicted from the moral of humanity, the moral of human to God, the moral of human to themself, the moral of human to other human beings, the moral of human to nature, the moral of human to time, and the moral of human in achieving physical and mental satisfaction.
\end{abstract}

Keywords: wawacan, structural, etnopedagogic 


\section{PENDAHULUAN}

Wawacan merupakan salah satu jenis sastra lama yang tersebar di wilayah Sunda. Mendalami wawacan bukan perkara yang mudah seperti halnya karya sastra lainnya. Padahal wawacan kaya akan pandangan hidup, filsafat dan nilai-nilai luhur yang perlu diperkenalkan kepada masyarakat. Tetapi, masyarakat sekarang jarang sekali membaca wawacan, akibatnya masyarakat sekarang kurang mengenal bentuk wawacan. Kurangnya media informasi yang mengenalkan karya sastra lama mengakibatkan masyarakat zaman sekarang tidak mengenal bentuk karya sastra lama. Oleh karena itu, perlu adanya upaya untuk mengenalkan wawacan kepada masyarakat.

Wawacan merupakan karya sastra lama yang dibentuk oleh beberapa jenis pupuh seperti dijelaskan oleh Iskandarwassid (1996:168) bahwa wawacan adalah cerita yang didangding, disajikan dalam bentuk puisi pupuh, umumnya panjang serta sering berganti pupuh, biasanya berbarengan dengan bergantinya episode.

Wawacan merupakan karya sastra hasil pemikiran manusia yang kaya akan nilai-nilai moral yang perlu diteliti untuk memberi gambaran kehidupan masyarakat. Seperti gambaran tentang moral manusia kepada Tuhan, moral manusia keoada diri pribadi, moral manusia kepada manusia lain, moral manusia kepada waktu, moral manusia keada alam, dan moral manusia dalam mencapai kebahagian lahir dan batin.

Sejalan dengan penelitian yang akan membahas etnopedagogik dalam wawacan bahwa etnopeagogik berpusat pada keunggulan manusia secara paripurna yang mempunyai pengalaman lahiran dan batiniah (Sudaryat, 2015:124). Karena mempunyai pengalaman lahir dan batin, pusat etnopedagogik Sunda menciptakan catur diri insan selaku manusia unggul, yaitu pengkuh agamana (spiritual quotient), luhung elmuna (intelectual quotient), jembar budayana (emotional quotient), dan rancage gawena (actional quotient).

Catur diri insan merujuk kepada moral yang menjadi pandangan hidup orang Sunda, yaitu moral manusia kepada Tuhan (MMT), moral manusia kepada diri pribadi (MMP), moral manusia kepada manusia lain (MMM), moral manusia kepada waktu (MMW), moral manusia keada alam (MMA), dan moral manusia dalam mencapai kebahagian lahir dan batin (MMLB) (Warnaen dkk, 1987:8).

Sebagai cerita dalam bentuk tulisan, Wawacan Mahabarata bisa dianalisis dari segi struktur dan nilai-nilai moral dalam lingkup etnopeadgogik. Sehubungan dengan hal tersebut, penelitian ini diberi judul "Wawacan Mahabarata Karya R. Memed Sastrahadiprawira dkk. (Kajian Struktur dan Etnopedgogik).

Penelitian ini akan menjelaskan gambaran isi cerita Wawacan Mahabarata; struktur cerita Wawacan Mahabarata; dan nilai etbopedagogik yang terkandung dalam Wawacan Mahabarata.

Tujuan umum penelitian ini untuk mengetahui dan memaparkan jenis karya sastra lama yang berupa wawacan. Secara khusus penelitian ini untuk memaparkan Wawacan Mahabarata berdasarkan isi cerita, struktur cerita, dan nilai etnopedagogiknya.

Penelitian ini sangat bermanfaat bagi secara teortis maupun secara praktis. Secara teoretis, hasil penelitian ini dapat dimanfaatkan untuk dijadikan dokumentasi dalam perkembangan sastra Sunda, khususnya karya sastra Sunda lama yang berbentuk wawacan. Penelitian ini pun dapat dijadikan sebagai sumber referensi bagi penelitian karya sastra Sunda lama. Secara praktis, hasil penelitian ini dapat dimanfaatkan bagi masyarakat untuk memberi pengetahuan tentang wawacan dan bagi peneliti dapat dijadikan sebagai penambah pengetahuan mengenai struktur dan nilai etnopedagogik wawacan. 


\section{METODE}

Sumber data dalam penelitian ini adalah buku Wawacan Mahabarata karya R. Memed Sastrahadiprawira, R. Satjadbrata, dan M.A. Salmun, yang disadur dari Cerita Mahabarata karya Wyasa. Buku ini diterbitkan oleh Balai Pustaka tahun 1949, ukuran buku 17,7 x $23,3 \mathrm{~cm}$, tebalnya 284 halaman.

Dalam penelitian ini digunakan metode deskriptif untuk mendeskripsikan hasil analsisi Wawacan Mahabarata.

Instrumen pengumpul data yang digunakan dalam penelitian ini adalah kartu data. Untuk mengumpulkan data digunakan teknik studi pustaka. Data yang terkumpul dianalisis dengan teknik analisis unsur langsung.

Penelitian terhadap Wawacan Mahabarata dilakukan elalui beberapa langkah, yakni (1) memperhatikan data yang telah dikumpulkan; (2) membuat klasifikasi data berdasarkan struktur dan nilai etnopedagogik; (3) menganalisis wawacan berdasarkan struktur cerita dan nilai etnopedagogik; (4) mendeskripsikan wawacan Mahabarata berdasarkan hasil analisis; dan (5) menafsirkan dan menyimpulkan struktur cerita dan nilai etnopedagogik.

\section{HASIL DAN PEMBAHASAN}

\section{Analisis Struktur Wawacan Mahabarata}

Anaisis struktur Wawacan

Mahabarata terbagi menjadi dua bagian, yaitu analisis struktur formal dan analisis struktur naratif.

\section{Analisis Struktur Formal Wawacan Mahabarata}

Dalam menganalisis struktur formal Wawacan Mahabarata dignakan teori Hermansoemantri dalam Ruhaliah (2013:14) yang menyatakan bahwa wawacan sebagai bentuk pupuh dan dalam struktur penulisan harus memperhatikan patokan guru lagu, guru wilangan, watak, dan sasmita pupuh.
Pupuh dalam Wawacan Mahabarata terdiri atas sebelas jenis pupuh dan 2842 bait. Pupuh yang ada dalam Wawacan Mahabarata yaitu (1) Kinanti, (2) Sinom, (3) Asmarandana, Dangdanggula, (5) Mijil, (6) Pucung, (7) Maskumambang, (8) Pangkur, (9) Durma, (10) Magatru, dan (11) Wirangrong.

Hasil analisis berasarkan guru lagu dan guru wilangan ditemukan pupuh yang sesuai dengan aturan dan pupuh yang tidak sesuai dengan aturan. Pupuh yang sesuai dengan aturan adalah pupuh Magatru dan pupuh Pucung. Sementara, pupuh yang tidak sesuai dengan aturan adalah pupuh Asmarandana, Dangdanggula, Dura, Kinanti, Maskumambang, Mijil, Pangkur, Sinom, dan pupuh Wirangrong.

Pertama, aturan penulisan pupuh Asmarandana yaitu 8-i, 8-a, 8-e/o, 8-a, 7-a, 8-u, dan 8-a. Kesalahan penulisan terdapat pada bait ke-1 larik ke-3. Kedua, aturan penulisan pupuh Dangdanggula yaitu 10-i, 10-a, 8e/o, 7-u, 9-i, 7-a, 6-u, 8-a, 12-i, dan 7 -a. Kesalahan penulisan terdapat pada bait ke-4 larik ke-9 dan bait ke-11 bait ke-5 . Ketiga, aturan penulisan pupuh Durma yaitu 12-a, 7-i, 6-a, 7-a, 8-i, 5-a, dan 7-i. Kesalahan penulisan pupuh durma terdapat pada bait ke-10 larik ke-6. Keempat, aturan penulisan pupuh Kinanti yaitu 8-u, 8-i, 8-a, 8-i, 8-a, dan 8-i. Kesalahan penulisan pupuh Kinanti terdapat pada bait ke-7 larik ke-3, bait ke-12 larik ke-3, dan bait ke-17 larik ke-2. Kelima, aturan penulisan pupuh Maskumam- bang yaitu 12-i, 6-a, 8-i, dan 8-a. Kesalahan penulisan pupuh Maskumambang terdapat pada bait ke-10 larik ke-1. Keenam, aturan penulisan pupuh Pangkur yaitu 8-a, 11-i, 8-u, 7-a, 12-u, 8-a, dan 8-i. Kesalahan penulisan pupuh Pangkur terdapat pada bait ke-10 larik ke-1 dan bait ke-12 larik ke-2. Ketujuh, aturan penulisan pupuh Sinom yaitu 8-a, 8-i, 8-a, 8-i, 7-i, 8-u, 7-a, 8-i, dan 12-a. Kesalahan penulisan pupuh Sinom terdapat pada bait ke-2 larik ke-6. Aturan penulisan pupuh Wirangrong yaitu 8-i, 8-o, 
8-u, 8-i, 8-a, dan 8-a. Kesalahan penulisan pupuh Wirangrong terdapat pada bait ke-4 larik ke-1.

Hasil analisis watak pupuh menunjukkan bahwa pupuh Asmarandana menggambarkan saling mengasihi dan kasih sayang; pupuh Dangdanggula menggambarkan keagungan dan kebahagiaan; pupuh Durma menggambarkan marah dan perang; pupuh Kinanti menggambarkan keprihatinan; pupuh Magatru menggambarkan keprihatinan; pupuh Maskumambang menggambarkan nelangsa dan keprihatinan; pupuh Pangkur menggambarkan nasu, amarah, dan perang; pupuh Pucung menggambarkan ajaran; pupuh Sinom menggambarkan kegembiraan dan kesenangan; serta pupuh Wirangrong menggambarkan rasa malu.

Hasil analisis sasmita pupuh ditemukan ada dua sasmita pupuh yang digunakan dalam Wawacan Mahabarata, yaitu dangdanggula untuk menggambarkan penggantian pupuh Dangdanggula dan megat untuk mengambarkan penggan- tian pupuh Magatru.

\section{Analisis Struktur Naratif Wawacan Mahabarata}

Dalam menganalisis struktur naratif Wawacan Mahabarata digunakan teori dari Robert Stanton (2012:20) yang menyebutkan bahwa struktur prosa fiksi terdiri atas tema, fakta cerita (tokoh, latar, dan alur), serta sarana sastra. Tetapi, dalam penelitian ini hanya dianalisis tema dan fakta ceritanya saja karena dianggap cukup untuk mengetahui nilai etnopedagogik.

Berdasarkan analisis struktur cerita dalam Wawacan Mahabarata ditemukan bahwa tema cerita adalah 'kehidupan sosial'. Hal ini terlihat dari konflik cerita yang menggambarkan kehidupan di lingkungan kerajaan Astina dan kerajaan Amarta.

Tokoh cerita dalam Wawacan Mahabarata dilihat dari kedudukannya di kerajaan sebagai kelompok Pandawa dan kelompok Kurawa serta tokoh-tokoh di sekitar kedua kelompok tersebut. Tokohtokoh cerita yang utama dalam Wawacan Mahabarata adalah Yudistira, Bima, Aruna, Suyudana, Kresna, Bisma, Destarata, Sakuni dan Dorna.

Tokoh cerita tambahan adalah Sentanu, Setyawati, Pandu, Pratipa, Prabu Hasti, Kuru, Barata, Dasa, Abiyasa, Prasara, Citragada, Wicitrawirya, Amba, Ambika, Ambalika, Salwa, Dewa Siwa, Srikandi, Destarata, Drupada, Suharta, Rara Rugu, Dewi Kunti, Basudewa, Bismaka, Sura, Ugrasena, Dewi Madrim, Salya, Gandari, Batara Darma, Batara Bayu, Batara Indra, Batara Aswin, Nakula, Sadewa, Dursasana, Dulasa, Karna, Widura, Baradwaya, Aswatama, Ekalaya, Batara Surya, Batara Guru, Adirata, Purocana, Jurumudi, Hidimbi, Hidimba, Gatitgaca, Baka, Erawan, Ijrapa, Drupadi, Destajumena, Baladewa, Kresna, Subadra, Buta, Kowara, Ulupi, Rawan, Abimanyu, Waruna, Agni, Jarasanda, Supala, Damagosa, Srutaswara, Maitreya, Sanyaya, Dewi Uma, Baradaswa, Nala, Damayanti, Lomasa, Sukania, Kama, Markadea, Sawitri, Batara Yama, Banaspati, Kangka, Balawa, Wrehanala, Dama Gratika, Tantripala, Malini, Kicaka, Utara, Utari, Setyaki, Nyai Rada, Susarma, Trigarta, Bagadata, Buriswara, Soma, Jayadata, Sudaksina, Brehadbale, Behadnata, Citragada, Kretawarma, Nila, Krepa, Destraketu, Jayasena, Hiranyawarma, Rukma, Matsyapati, Wratsangka, Seta, Dewa Wisnu, Srenggi, Wersaya, Jayadrata, Lasmana, Pratipea, Gayaksa, Saraba, Lembusana, Lembana, Kala Srenggi, Kalana Sura, Raa Bargawa, Badega, Warsa Komara, Kerpa, Kertawarma, Pancawala, Usinara, Jayadagni, Rinuka, Parikesit, Kali, Dwapara, Narada, Yadawa, Samba, Jara, Daruka.

Dilihat dari perilaku tokoh terdiri atas tokoh protagonis dan tokoh antagonis. Tokoh protagnis merupakan tokoh-tokoh 
yang berperilaku psositif, sedaangkan tokoh antagonis merupakan tokoh-tokoh yang berperilaku negatif. Di antara tokohtokoh antagonis dalam Wawacan Mahabarata yaitu Setyawati, Dewi Amba, Kurawa, Suyudana, Karna, Sangkuni, Hidimba, Dorna, dan Aswatama.

Dilihat dari wataknya, tokoh cerita dibedakan atas pelaku kompleks seperti Sentanu, Setyawati, Bisma, Bima, Suyudana, Drupada, Dorna, Arjuna, Yudistira, Karna, Kresna, Kurawa, Gatotgaca, Aswatama, dan Sakuni. Tokoh sederhana dalam cerita Wawacan Mahabarata yaitu Prabu Hasti, Dewi Amba, Suharta, Dewi Kunti, Supala, Dursasana, Drupadi, Batara Indra, dan Banaspati.

Dilihat dari kriterianya dibedakan atas tokoh statis dan tokoh dinamis. Tokoh dinamis yaitu Dorna, Setyawati, Hidimbi, Bima, Sakuni, Karna, Yudistira, Bisma, dan Destarata.

Dilihat dari pencerminan, dibedakan tokoh tipikal dan tokoh netral. Tokoh tipikal yaitu Pandawa, Yusidtira, Arjuna, Bima, Sentanu, Bisma, Setyawati, Abiayasa, Kresna, Suyudana, Destarata, dan Sakuni.

Analisis latar dalam Wawacan Mahabarata terbagi menjadi latar tempat, waktu, dan latar sosial. Latrar tempat terdiri atas lingkungan kerajaan yang berada dalam lingkup negara Hindustan. Latar waktu terdiri atas waktu berdasarkan titimangsa sepeti hiji mangsa, hiji wanci, hiji waktos, lima ratus taun ka tukang, tengah poe, poe kadua, poe katilu, poe kasapuluh, beurang, peuting, burit, siangwengi, enjing-enjing, subuh, magrib, sareuna, isukna, isukan, usum halodo, dan katiga. Berdasarkan durasi yaitu sataun, tilu welas taun, dua belas taun, tujuh taun, tilu rebu taun, lima welas taun, dan sasasih. Latar sosial yaitu keadaan kerajaan-kerajaan di Hindustan, khususnya kerasaan Astina.
Analisis alur dalam cerita Wawacan Mahabarata terdiri dari sebelas episode dengan menggunakan alur maju.

\section{Analisis Etnopedagogik dalam Wawacan Mahabarata}

Analisis etnopedagogik dalam Wawacan Mahabarata mengacu kepada moral kemanusiaan, yaitu moral manusia kepada Tuhan (MMT), moral manusia kepada diri pribadi (MMP), moral manusia kepada manusia lain (MMM), moral manusia kepada waktu (MMW), moral manusia keada alam (MMA), dan moral manusia dalam mencapai kebahagian lahir dan batin (MMLB) (Warnaen dkk, 1987:8). Keenam moral kemanusiaan tersebut masing-masing dipaparkan sebagai berikut.

Pertama, analisis moral manusia terhadap Tuhan tergambar dari kepercayaan masyarakat kepada Dewa. Juga masyaraat yang taat pada ajaran agama.

Kedua, analisis moral manusia kepada diri pribadi tergambar dari sifatsifat yang dimiliki oleh para tokoh cerita seperti adil, jujur, pemarah, bijaksana, teguh pendirian, dendam, sabar, setia, tidak egois, dan iri hati.

Ketiga, analisis moral manusia kepada manusia lain tergambar dari sikap tokoh terhadap tokoh lain yang saling menolong, taat kepada aturan, tidak pilih kasih, rukun sesama keluarga, tidak mengambil hak orang lain, saling memaafkan, saling menghargai, dan saling mempercayai.

Kelima, analisis moral manusia terhadap alam tergambar dari sikap para tokoh dalam memanfaatkan sesuatu yang berhubungan dengan alam termasuk memanfaatkan tumbuh-tumbuhan.

Keenam, analisis moral manusia terhadap waktu tergambar dari sikap para tokoh dalam memanfaatkan dan menghargai waktu.

Ketujuh, analisis moral manusia dalam memncapai kebahagiaan lahir dan 
batin tergambar dari sikap tokoh yang beruasaha untuk mencapai keinginannya walaupun dengan resiko yang besar.

\section{Simpulan}

Struktur formal Wawacan Mahabarata berasarkan guru lagu dan guru wilangan ditemukan pupuh yang sesuai dengan aturan dan pupuh yang tidak sesuai dengan aturan. Pupuh yang sesuai dengan aturan adalah pupuh Magatru dan pupuh Pucung. Sementara, pupuh yang tidak sesuai dengan aturan adalah pupuh Asmarandana, Dangdanggula, Dura, Kinanti, Maskumambang, Mijil, Pangkur, Sinom, dan pupuh Wirangrong. Struktur narataf Wawacan Mahabarata mengacu kepada tema, tokoh, latar, dan alur. Analisis tokoh dilihat dari kedudukan, watak, kriteria, dan penceriman. Analisis latar terdiri atas latar tepat, waktu, dan latar sosial. Analisis etnopedagogik dalam Wawacan Mahabarata mengacu kepada moral kemanusiaan, yaitu (1) moral manusia kepada Tuhan, yang tercermin dari kepercayaan kepada dewa; (2) moral manusia kepada diri pribadi, yang tercermin dari karakter tokoh; (3) moral manusia kepada manusia lain, yang tercemin dari sikap tokoh kepada tokoh lain; (4) moral manusia kepada waktu, yang tercermin dari sikap tokoh yang memanfaatkan dan menghargai waktu; (5) moral manusia kepada alam, yang tercermin dari sikap tokoh yang memanfaatkan alam; dan (6) moral manusia dalam mencapai kebahagian lahir dan batin, yang tercermin dari sikap tokoh yan$\mathrm{g}$ berusaha mencapai keinginannya.

\section{PUSTAKA ACUAN}

Iskandarwassid. (1996). Kamus Istilah Sastra. Bandung: CV Geger Sunten.

Ruhaliah. (2013). Sejarah Sastra Sunda. Bandung: Jurusan Pendidikan Bahasa Daerah FPBS UPI.

Sudaryat, Yayat. (2015). Wawasan Kesundaan. Bandung: Jurusan Pendidikan Bahasa Daerah FPBS UPI.

Stanton, Robert. (2012). Teori Fiksi. Yogyakarta: Pustaka Pelajar

Warnaén, Suwarsih spk. (1987). Pandangan Hidup Orang Sunda Seperti Tercermin Dalam Tradisi Lisan dan Sastra Sunda. Bandung: Departemen Pendidikan dan Kebudayaan Direktorat Jenderal Kebudayaan Bagian Proyek Penelitian dan Pengkajian Kebudayaan Sunda.

\section{Ucapan Terimakasih}

Saya ucapkan terimakasih pada Allah S.W.T. yang terus memberikan nikmat sehingga makalah ini rampung dikerjakan. Terimakasih pada seluruh dosen Prodi. Pendidikan Bahasa dan Budaya Sunda, terutama pada Dr. H. Yayat Sudaryat, M.Hum dan Dr. Dedi Koswara, M. Hum. yang memberi masukan perihal tulisan ini. Terimakasih juga kepada pihak jurnal yang telah bersedia menerbitkan artikel ini. 